\title{
Opioid and Polydrug Use Among Patients in Opioid Maintenance Treatment
}

This article was published in the following Dove Press journal:

Substance Abuse and Rehabilitation

\author{
Siv-Elin Leirvaag Carlsen (1D) \\ Linn-Heidi Lunde ${ }^{1,2}$ \\ Torbjørn Torsheim ${ }^{3}$ \\ 'Department of Addiction Medicine, \\ Haukeland University Hospital, Bergen, \\ Norway; ${ }^{2}$ Department of Clinical \\ Psychology, University of Bergen, Bergen, \\ Norway; ${ }^{3}$ Department of Psychosocial \\ Science, University of Bergen, Bergen, \\ Norway
}

Purpose: Opioid maintenance treatment reduces a person's use of heroin. However, frequent substance use in treatment is a problem.

Aim: To examine the association between opioid maintenance treatment and opioid/polydrug use, and whether social factors, adverse experiences, social resources, and quality of life are associated with opioid/polydrug use during the first 12 months in treatment.

Patients and Methods: Forty-seven participants from treatment units in Bergen, Norway participated in five waves of data collection. Every third month, a structured face-to-face interview collected self-reported data on sociodemographic characteristics, opioid/polydrug use, participants' social resources or adverse experiences, and quality of life. Data were collected as part of KVARUS, the National Quality Register for Substance Abuse Treatment. A multilevel binary logistic regression analysis was conducted to examine the association of opioid/polydrug use and time in current treatment. The analysis included regressions of opioid/polydrug use on time-invariant baseline adverse experiences and social resources, and time-varying reports of quality of life.

Results: There was a significant negative association between time in treatment and use of opioids, $b=-0.89, S E=0.19, p=<0.01$. Furthermore, a negative association of age at substance use on polydrug use was found, $b=-0.40, S E=0.19, p=0.03$. A higher overall quality of life was significantly associated with lower odds of opioid use during opioid maintenance treatment, $b=$ $-0.62, S E=0.23, p=<0.01$. Social dimensions, participants' adverse experiences, and social resources were not associated with polydrug or opioid use.

Conclusion: Opioid maintenance treatment is associated with lowered opioid use, but to a lesser degree with polydrug use. Our findings add quality of life as an important factor that should be given particular attention because it can offer insight to aspects that can affect the patients' opioid use.

Keywords: opioid maintenance treatment, polydrug use, opioid use, patient reported outcome measures, quality of life

\section{Introduction}

Opioid Maintenance Treatment (OMT) reduces use of heroin, ${ }^{1-3}$ retains patients in treatment, $^{3,4}$ and decreases criminal activity ${ }^{4,5}$ and mortality. ${ }^{2,6}$ Today, OMT is the most common and effective treatment for opioid dependence. ${ }^{3,7-10}$ To illustrate the effectiveness of OMT, Tran, Ohinmaa, Mills, et al ${ }^{11}$ found that the proportion of self-reported opioid use among patients in OMT with continued opioid use decreased from $99.7 \%$ from baseline to $14.6 \%$ at 9 -month follow-up.

The positive effect of OMT on heroin reduction might not generalize to reduced use and misuse of other legal and illegal substances. Several sources reported misuse of alcohol, benzodiazepines (BZD), amphetamines, cannabis, cocaine, and OMT
Correspondence: Siv-Elin Leirvaag

Carlsen

Department of Addiction Medicine,

Haukeland University Hospital, PO Box

1400, Bergen 5021, Norway

Tel +4755970l 76

Fax +47559701 0I

Email leis@helse-bergen.no 
medications. ${ }^{7,10,12-14}$ Synthetical opioids such as methadone, buprenorphine, and fentanyl are increasingly misused. ${ }^{10}$ Frequent substance use and polydrug use in OMT is a problem, ${ }^{8,9,15}$ and such use is associated with dropout from OMT. ${ }^{16,17}$ Drug use in early OMT is indicative of problematic or negative response to treatment. White, Campbell, Spencer, Hoffman, Crissman, DuPont ${ }^{18}$ found that OMT patients with positive test for polydrug use had quadrupled the attrition rate, with the highest attrition rate among patients who used opiates or non-prescribed BZD, $46 \%$ and $42 \%$, respectively. In contrast, those without positive drug tests had a $10 \%$ attrition rate.

The magnitude of polydrug use among OMT patients has received little research attention. ${ }^{7}$ A study showed that among OMT patients in Canada, 93.3\% had used illicit substance, and $85 \%$ tested positive for polydrug use indicated by $\geq 2$ illicit drug classes in the same test. ${ }^{17}$ Soyka, et $\mathrm{al}^{2}$ found that OMT patients in Germany increased use of alcohol, cannabis, and cocaine from baseline to 12 months, and at six-year follow-up. The study also showed that patients underreported the use of BZD, and urine tests identified 20\% used BZD while in $\mathrm{OMT}^{2}$ Specka, et al ${ }^{12}$ found that $25 \%$ of all OMT patients had a constantly high BZD-positivity rate, and usually in combination with additional substances. A recent study among 434 patients in opioid agonist treatment in Ukraine showed that $23 \%$ injected drugs the previous 30 days, primarily opioids, and of these $40 \%$ had polydrug use with opioids, stimulants, and alcohol. ${ }^{19}$ A Chinese study showed that $74.6 \%$ of OMT patients used opioids more than once during the 12 months after treatment initiation. ${ }^{20}$ Wagner, et $\mathrm{al}^{7}$ found that $51 \%$ of patients with minimum 1 week in OMT had positive tests for at least one non-prescribed substance, and 32\% tested positive for substances that were not part of the routine drug screening, such as Pregabalin.

There are multiple determinants for substance use, e.g. polydrug and/or opioid use, among OMT patients. Substance use refers to the use of one substance, either illegal or legal, while polydrug use refers to the use of multiple substances consumed sequentially or at the same time. ${ }^{21}$ Having a history of polydrug use, history of injecting ${ }^{22}$ and a desire to get intoxicated predict continued polydrug use during OMT. However, Moratti, Kashanpour, Lombardelli, Maisto ${ }^{23}$ suggest that experience of euphoria or pleasure is seldom the main reason for substance and polydrug use. Other potential factors are self-treatment of opioid dependence where the person tries to reduce withdrawal symptoms and cravings, ${ }^{24}$ the type of OMT medication, ${ }^{22}$ and inadequate dosage. ${ }^{15,22,23,25,26}$ Side effects of OMT medications can lead patients to prefer alternative to OMT medication. ${ }^{27}$ Tran, et al $^{11}$ found that ongoing substance abuse was significantly predicted by peer pressure, cravings, having health concerns and receiving treatment for tuberculosis.

In addition to these individual factors, social conditions might be contributing factors in polydrug use during OMT as well. Poorer social conditions, such as no work and income, and ongoing substance use have been associated with injected buprenorphine among OMT patients. ${ }^{28}$ According to Kopak, Proctor, Hoffmann ${ }^{29}$, patients age (younger than 25 years), low income (earning less than a high-school diploma), marital status (never been married), and employment status (unemployed) were important indicators in relation to posttreatment substance use. Lack of psychosocial support during treatment is also associated with injecting use of intoxicating substances. ${ }^{22}$ Maintaining contact with active drug users and participating in a drug-use lifestyle are negative effects of polydrug use which can reduce the probability of successful outcome from OMT. ${ }^{30}$ Besides, a childhood with only one or no parents, not living in a stable relationship and being dissatisfied with treatment are significantly associated with sniffing of buprenorphine among OMT patients. ${ }^{31}$

Social and environmental influences can be a part of multiple causes for ongoing substance abuse among patients in OMT. As concurrent substance use might lower retention rate in OMT, ${ }^{16,18}$ it is important to understand and examine the determinants of concurrent use. Knowledge about these factors is a perquisite for improving interventions, retention and outcomes of OMT. On this background, our study addresses the following research objectives:

(a) to examine the association between OMT and subsequent substance/polydrug use and,

(b) to examine whether social factors such as social background, adverse experiences, social resources, and quality of life (QOL) are associated with substance and polydrug use during the first 12 months after enrolment in OMT.

\section{Materials and Methods}

\section{Sample}

Eligible participants were first-time OMT patients in the catchment area of Haukeland University Hospital, Bergen, Norway. In 2018 there were 1080 OMT-patients in this catchment area. Approximately 100 new patients were enrolled on a yearly basis. OMT patients were recruited 
from eight outpatient OMT units, during two periods: January to December 2013, and September 2015 to June 2016. The majority of participants were outpatients, but some participants were imprisoned. At the outpatient unit, patients picked up their daily medicine and had a short conversation with one of the OMT staff, while participants in prison got their medication from health professionals or prison staff. Participants received either buprenorphine (4 to $20 \mathrm{mg} /$ day) or methadone (80 to $100 \mathrm{mg} /$ day). Two participants got a muscle injection of extended-release naltrexone once a month.

Inclusion criteria were first time admittances to OMT, opioid dependence according to ICD-10 or DSM-IV, age > 18 years, commencement of OMT medication (buprenorphine or methadone) before the first registration. Lack of competence to consent was the only exclusion criterion. One hundred and 39 OMT patients were contacted and invited to participate in our study. All of these 139 fulfilled the inclusion criteria. Of these, 15 declined to participate, while 77 OMT patients did not respond to the invitation. Forty-seven self-recruited opioid-dependent individuals in OMT were enrolled in the study. Data from these 47 participants were included in the analysis up to the time participants completed the research participation. Participants received a lottery ticket for every fulfilled data point. At the 12-month data point, participants received a gift card valued for 200 NOK (approximately 22 USD or 22 EUR) in addition to the lottery ticket.

During the first year of data collection, 10 participants dropped out. Five participants dropped out without reason, three withdrew due to lack of interest, one was excluded due to cognitive impairment and inability to provide consent, and one participant was impossible to get in touch with. For complete information see Carlsen, Lunde, Torsheim. ${ }^{32}$

\section{Data Collection}

Structured face-to-face interviews were completed by using the KVARUS questionnaire (National Quality Register for Substance Abuse Treatment). The KVARUS applies to individuals with a substance use disorder enrolled in treatment, and data in KVARUS are patients' subjective perceptions on given topics. The KVARUS is described in detail elsewhere, see Carlsen, Lunde, Torsheim. ${ }^{32}$

We utilized data from a three-monthly interval from baseline (T0) through the first 12-month follow-up (T1-T4, where $\mathrm{T} 1$ is after 3 months, T2 is after 6 months, T3 is after 9 months, and T4 after 12 months). Between 169 and 193 observations were collected from a total of 47 participants. These data were analysed and distributed as follows: 47 participants at T0, 38 participants at T1 and T2, 34 participants at T3 and 36 participants at $\mathrm{T} 4$.

Participants provided written informed consent. The principal investigator had the main responsibility for data management. The study was approved by the Regional Committee for Medical and Health Research Ethics (2013/429/REK South-East C).

\section{Measures}

In the current study, information on sociodemographic characteristics, substance use, social resources, adverse experiences, and QOL was collected.

Measured sociodemographic characteristics were level of education (no education/primary-secondary school/high school, higher education), marital status (single/cohabitant/ boy-girlfriend), and living situation (own apartment/permanently with family/temporary living arrangement/homeless).

Substance use over the last 30 days was measured by the participants' self-reported 1) opioid use such as heroin, non-prescribed opioids, like methadone, buprenorphinenaloxone (Suboxone ${ }^{\circledR}$ ), buprenorphine, morphine, other opioids, or overuse or misuse of prescribed opioids, and 2) use of substances such as alcohol, cannabis, BZD, GHB/GBL, hallucinogens, amphetamine, cocaine, and other stimulants. Participants' use of OMT medication (methadone, buprenorphine-naloxone $\left(\right.$ Suboxone $^{\circledR}$ ) or buprenorphine) as prescribed was not considered as opioid use. However, participants' self-reported misuse or overuse of opioids were categorised as opioid use, and use of other substances were categorised as polydrug use.

Significant life events can be experienced as social resources or adverse experiences. Adverse experiences are traumas or life events that the participants consider as having a negative impact on their current life. Dropout from school, addictions in participants' close family, neglect and being under care are indicators of adverse experiences found in KVARUS. Examples of social resources measured in KVARUS are support from family members, having drugfree friends, a safe and good housing situation and being in a stable relationship. These indicators were measured by "yes" or "no" responds. The yes responds to the various indicators of social resources were grouped into one variable, measuring the total social resources the participants accessed. In addition, the yes responds for the adverse experience indicators were grouped into one variable measuring the total adverse experience participants had been exposed to. 
The current study used general and domain-specific measures of QOL. Overall QOL was measured by the item: How would you rate your QOL as a whole $?^{33}$ The questions to measure the domain-specific QOL were: How satisfied are you with: 1) your relationship with friends, ${ }^{33-35}$ 2) housing, ${ }^{33,36}$ 3) your health, ${ }^{33,34}$ 4) leisure, ${ }^{36}$ and 5) financial situation. ${ }^{36}$ Responses were given on a 5-point Likert-type response scale, ranging from $1=$ "very dissatisfied" to $5=$ "very satisfied" at each measurement point.

\section{Data Analysis}

To predict dichotomized outcomes from categorical and continuous predictors we used multilevel binary logistic regression analysis, as implemented in the Stata melogit program. The analysis process was conducted in two stages: in the first stage, the objective was to examine the association of use of opioids or other substances and time in treatment. We conducted a two-level binary logistic regression with polydrug use/opioid use as the dependent variable. The independent variables were time (cumulative from $\mathrm{T} 0$ to $\mathrm{T} 4$ ), overall QOL, level of education, marital status, and living situation.

The second stage of the main analysis included regressions of polydrug use/opioid use on time-invariant baseline, adverse experiences and social resource, and time-varying reports of QOL and social factors such as marital status, housing, and education. We also tested for associations between polydrug use/opioid use and participants selfreported social resources and adverse experiences. Various social life domains can be reflected in specific QOL indicators that are strongly related to global life satisfaction. ${ }^{35} \mathrm{We}$ therefore tested for specific QOL domains such as participants' relationships with friends, their health, leisure, housing, and financial situation.

The $\mathrm{n}$ varies in the different analyses due to nonresponse on some of the time-varying covariates included. For this reason, the current study used between 193 and 146 observations in the data analysis. To test whether there was a difference at baseline between participants who dropped out and participants who completed the study, we conducted a Fisher's exact test. A confidence interval of $95 \%$ was set, and a $p$-value of $<0.05$ was considered statistically significant in all the analyses.

\section{Results}

\section{Attrition}

There was attrition from baseline to 12-month follow-up. Five participants only completed baseline registration.
Four participants missed three data points, one participant missed two data points, and eight participants missed one data point. Twenty-nine participants completed all data points from $\mathrm{T} 0$ to $\mathrm{T} 4$.

There was no statistically significant association between attrition pattern and polydrug use from $\mathrm{T} 0$ to $\mathrm{T} 4$ (baseline to 12-month follow-up) by Fisher's exact test, baseline $p=0.60$, 3 months $p=1.000,6$ months $p=1.000,9$ months $p=1.000$, and 12 months $p=0.42$, respectively. Likewise, no significant difference was found from T0 to T3 (baseline to 9 months follow-up) between attrition pattern and illegal opioid use, $p=0.53, p=0.42, p=0.20, p=1.000$, respectively. However, patients that dropped out at T4 had a higher polydrug use at $\mathrm{T} 0$, compared to non-dropouts, $p=0.02$.

\section{Sociodemographic Characteristics}

Participants were mainly Norwegian men, $76.6 \%$, with a mean age of 37.8 years $(S D=8.58)$ at baseline. The mean age at substance use onset was 14.3 years $(\mathrm{SD}=$ 4.87 ), while age at opioid onset was 22.6 years $(S D=$ 6.80). At baseline, $78.7 \%$ of participants were not in a relationship. About half of the participants, $51.1 \%$, lived in their own apartment, while $29.8 \%$ had a temporary-living situation, e.g. prisons, rehabilitation homes or treatment institutions, and $14.9 \%$ lived with their family. With regard to the education level, $45 \%$ of the participants' had primary/ secondary school while $27.7 \%$ had high school as their highest education. Approximately half of the participants had children, $53.2 \%$; however, only $8.5 \%$ had custody for children under 18 years of age. About one-third, 29.7\%, had visitation rights. Other sociodemographic characteristics were reported in Carlsen, Torsheim. ${ }^{37}$ For sociodemographic distribution on study variables, see Table 1.

\section{Illegal Substance and Opioid Use}

At baseline, $70.2 \%$ of participants who reported substance use within the last 30 days stated opioids as the used substance. In this context, the use of opioids mainly consisted of heroin or illegal use of buprenorphine. The frequency of usage varied from single days to daily use of opioids during the last 30 days. In addition to opioid use, participants reported polydrug use that usually consisted of cannabis, BZD, amphetamine, and alcohol. Use of these illegal substances was also reported at the follow-up periods. Benzodiazepines and cannabis were often used in combination with other substances. Figure 1 shows the results from opioid and polydrug use on time. 
Table I Baseline Characteristics for First Time Enrollees in Opioid Maintenance Treatment

\begin{tabular}{|c|c|c|}
\hline & Mean/\% & SD \\
\hline Age & 37.8 & 8.58 \\
\hline \multicolumn{3}{|l|}{ Marital Status } \\
\hline Single & $78.7 \%$ & \\
\hline Cohabitant/married & $21.3 \%$ & \\
\hline \multicolumn{3}{|l|}{ Education Level } \\
\hline No education & $8.5 \%$ & \\
\hline Primary/secondary school & $44.7 \%$ & \\
\hline High school & $27.7 \%$ & \\
\hline Higher education & $19.1 \%$ & \\
\hline \multicolumn{3}{|l|}{ Substance Use } \\
\hline Age at substance use onset & 14.3 & 4.87 \\
\hline Age at opioid onset use & 22.6 & 6.80 \\
\hline Opioid use & $70.2 \%$ & \\
\hline Polydrug use & $66.0 \%$ & \\
\hline \multicolumn{3}{|l|}{ Significant Live Events } \\
\hline Social resources & 8.61 & 4.82 \\
\hline Adverse experiences & 9.82 & 4.47 \\
\hline \multicolumn{3}{|l|}{ Quality of Life } \\
\hline Overall Quality of Life & 2.27 & 1.41 \\
\hline \multicolumn{3}{|l|}{ Domain-specific Quality of Life } \\
\hline Housing & 3.14 & 1.48 \\
\hline Leisure & 3.02 & 1.23 \\
\hline Friends & 3.15 & 1.25 \\
\hline Health & 2.97 & 1.27 \\
\hline Financial situation & 2.14 & 1.10 \\
\hline
\end{tabular}

Note: Sample size domain-specific QOL vary between 44 and 47 participants, missing data from I to 3 participants.

There was no association of time, $b=-0.01, S E=0.16$, $C I[-0.33,0.30], p=0.93$, on polydrug use. However, a significant relationship between time and use of opioids was identified, $b=-0.89, S E=0.19, C I[-1.28,-0.50]$, $p=<0.01$. Participants had a significant reduction in opioid use during the first 12 months; especially within the first 3 months see Figure 1.

The result showed a significant relationship between age at substance use onset and polydrug use, $b=-0.40$, $S E=0.19, C I[-0.77,-0.02], p=0.03$, indicating that the older the age at onset the lower the polydrug use in OMT. However, no such association was found between age at opioid onset and opioid use.

\section{Social Background}

Multilevel binary logistic regression showed that marital status was not associated with polydrug use or opioid use.

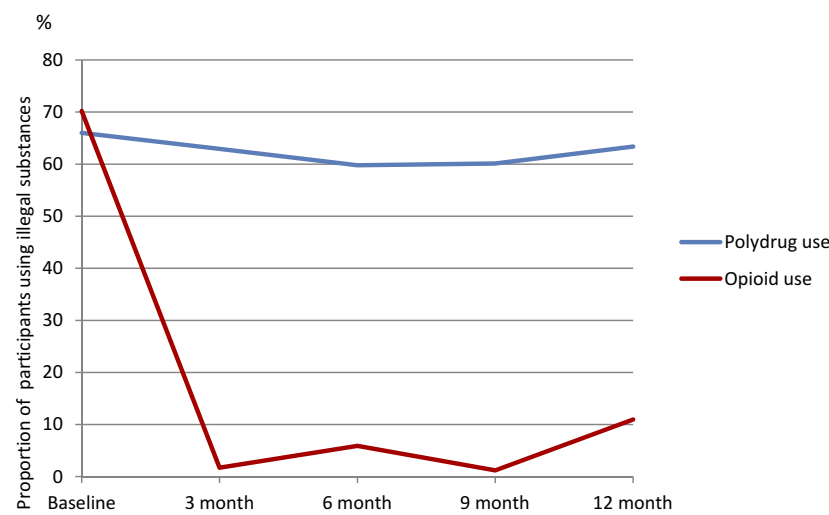

Figure I Polydrug use and opioid use regressed on time (follow-up time TI-T4). Note: Sample size baseline 47.

Education level was overall not related to polydrug or opioid use. Compared to other housing situations, we found that living in a treatment institution or in prison were significantly related to having less polydrug use, $b=-2.53, S E=0.81, C I[-4.13,-0.93], p=0.002$.

In the last sequence, a multilevel logistic regression tested the associations between the dependent variable and participants' social resources, their adverse experiences, age at substance onset, age at opioid onset, follow-up time, and QOL.

For opioid use, pre-baseline history of adverse experiences and social resources were not significantly associated with opioid use during OMT. Overall QOL during OMT was significantly associated with opioid use, indicating that higher QOL was related to lower odds of opioid use during OMT $b=-0.62, S E=0.23,95 \% C I[-0.16$, -0.22 ], $p=<0.007$.

Adverse experiences and social resources were not significantly related to polydrug use during treatment. However, age at substance use onset was significantly associated with polydrug use, see Table 2. No interrelations between the other independent indicators and polydrug use were identified.

Interaction effect analysis revealed no significant Time by Total adverse experiences interaction, Time by Total resources interaction, or Time by Age at substance use onset interaction (not shown in tables), indicating that these background factors did not moderate the slope of change in OMT.

In follow-up analysis we tested polydrug use/opioid use and domain-specific QOL indicators, such as housing, leisure, family and friends, health, and financial situation, but none of these specific domains of QOL were associated with opioid use or polydrug use. 
Table 2 Indicators for Opioid Use and Polydrug Use for Participants in OMT

\begin{tabular}{|c|c|c|c|c|c|c|c|c|c|c|c|c|}
\hline & \multicolumn{6}{|c|}{ Opioid Use ${ }^{a}$} & \multicolumn{6}{|c|}{ Polydrug Use ${ }^{b}$} \\
\hline & \multirow[t]{2}{*}{ B } & \multirow[t]{2}{*}{ SE } & \multirow[t]{2}{*}{$\mathbf{p}$} & \multirow[t]{2}{*}{$\mathbf{z}$} & \multicolumn{2}{|c|}{$95 \% \mathrm{Cl}$} & \multirow[t]{2}{*}{ B } & \multirow[t]{2}{*}{ SE } & \multirow[t]{2}{*}{$\mathbf{p}$} & \multirow[t]{2}{*}{$\mathbf{z}$} & \multicolumn{2}{|c|}{$95 \% \mathrm{Cl}$} \\
\hline & & & & & LL & UL & & & & & LL & UL \\
\hline Intercept & 4.08 & 1.82 & 0.025 & 2.24 & 0.50 & 7.66 & 5.75 & 2.09 & 0.006 & 2.74 & 1.64 & 9.86 \\
\hline Time $^{c}$ & -0.89 & 0.19 & 0.001 & -4.5 & -1.28 & -0.50 & -0.01 & 0.16 & 0.938 & -0.01 & -0.33 & 0.30 \\
\hline QOL & -0.62 & 0.23 & 0.007 & -2.68 & -1.07 & -0.16 & -0.22 & 0.21 & 0.288 & -1.06 & -0.65 & 0.19 \\
\hline Substance use onset & & & & & & & -0.40 & 0.19 & 0.035 & -2.11 & -0.77 & -0.02 \\
\hline Age of opioid onset & -0.07 & 0.04 & 0.088 & -1.71 & -0.15 & 0.01 & & & & & & \\
\hline Adverse experiences total & -0.10 & 0.06 & 0.139 & -1.48 & -0.23 & 0.03 & -0.12 & 0.10 & 0.256 & -1.14 & -0.33 & 0.08 \\
\hline Resources total & 0.05 & 0.06 & 0.333 & 0.97 & -0.05 & 0.17 & -0.12 & 0.10 & 0.229 & -1.2 & -0.31 & 0.07 \\
\hline
\end{tabular}

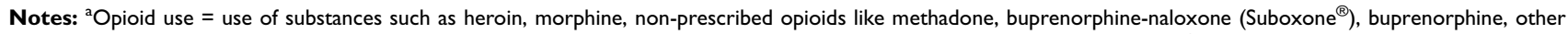
opioids, or overuse/misuse of prescribed opioids. Sample size 43 participants with 169 observations, number of missing data $4 .{ }^{\text {b }}$ Polydrug use $=$ multiple consumption of substances such as: alcohol, cannabis, BZD, GHB/GBL, hallucinogens, amphetamine, cocaine, and other stimulants. Sample size 46 participants with I80 observations, number of missing data I. ${ }^{\mathrm{C}}$ Time = change per 3-month period.

Abbreviations: $\mathrm{Cl}$, confidence interval; LL, lower limit; UL, upper limit.

\section{Discussion}

Our main finding is that OMT is significantly related to opioid use among opioid-dependent individuals', especially during the first year. This is also in line with previous studies. ${ }^{1,2,38}$ OMT aids the withdrawal symptoms and the continuous hunt for the next fix for the patients. The fact that some OMT patients have a concurrent opioid and/or polydrug use is a discussion of whether OMT patients' make use of the treatment or not, and this is of clinical, social, and political interest. Lack of psychosocial support has been associated with the use of legal and illegal substance use in OMT. ${ }^{22}$ Some participants in our study highlighted the treatment system in itself as a reason for polydrug use. They experienced "being a part of a machinery", where the treatment consisted of daily distribution of medicine and a brief conversation with the staff at the outpatient unit. Participants expressed a need for psychological treatment, more medical follow-up with a more flexible tapering of illegal use, such as BZD, and help with social challenges, e.g. related to daily activities as well as assistance with their housing situation. On the basis of lack of psychosocial treatment and inadequate help in OMT, many OMT patients used their well-known coping strategies, namely polydrug use. One solution to reduce patients' opioid use and/or polydrug use can perhaps be found in the actual treatment system, i.e. what type of treatment, the treatment content and treatment alternative patients are offered as well as addressing other burdens they bring along into treatment. Norway has a Cooperation reform (Samhandlingsreform) that was implemented to develop a better public health, prevention and a better health and care services. ${ }^{39}$ This Cooperation reform provides guidelines for interaction across municipal and national institutions, but these strategies might not be very effective when it comes to OMT patients. In addition, Lions, Carrieri, Michel, et $\mathrm{al}^{40}$ found that a good relation to their physician could help OMT patients to abstain from none-prescribed opioid during treatment.

Abstinence has been the main objective for treatment of opioid addiction as well as a measure and outcome of treatment success. ${ }^{41,42}$ Nevertheless, addictions are often intertwined with social, economic, health and mental issues, and a more holistic and patient-oriented perspective has recently been emphasized. According to Van den Brink, Haasen ${ }^{43}$ only motivated patients with sufficient social support and stable living situations would benefit from abstinenceoriented interventions. Considering this, the treatment system and clinicians might have to accept that not all patients want to, or are motivated to stop using substances and that abstinence, for many, is a utopia. From a harm reduction perspective, perhaps the treatments system should, to a greater extent than today, help OMT patients to gain a controlled polydrug use, and if tapering of OMT medication and abstinence was desired it should be seen as a treatment bonus. The definition of a successful treatment may vary from the patients' perspective to the clinicians' perspective. Outcome measures that take the perspective of the patient's into account will be beneficial, and QOL is such a measure. To improve the QOL for opioid-dependent individuals is one of the goals for OMT in Norway. ${ }^{44}$ Our research found that overall QOL has a specific relation to opioid use, and overall QOL seems to be an important 
indicator across time in OMT. This adds to the range of research that emphasizes the importance of QOL as an outcome measure. $^{45,46}$

Mutasa $^{47}$ found several factors for OMT patient's concurrent substance use: peer association, social exclusion, unemployment, poor education, poverty, personality trait (such as low self-esteem and anxiety), and lack of structure in everyday life. Brewer, Catalano, Haggerty, Gainey, Fleming ${ }^{48}$ found that employment problems/unemployment and relationship with substance using peers did predict longitudinally continued substance use. We found that participants' social characteristics were associated with neither opioid nor polydrug use during the first 12 months of OMT. Our results are in line with Brewer, et $\mathrm{al}^{48}$ who showed that most of the demographic variables had weak or non-existing associations with continued substance use. There is evidence for an association between traumatic experiences from childhood and substance abuse, ${ }^{49-51}$ and age at first injection drug use. ${ }^{52}$ In a previous publication, ${ }^{37}$ we found that OMT participants differed in their exposure to adverse events, and this exposure was systematically related to age at opioid use onset. However, we did not find any associations between participants' adverse experiences or social resources, and their polydrug or opioid use during the 12-month follow-up.

Previous research identified an association between young age and polydrug use. ${ }^{53,54}$ This association is complex and potential factors can be: being young and "undergoing renovation" you might be more vulnerable compared to when one is older. Besides, a feature of being young is to be a bit more exploratory and maybe being more exposed to adverse experiences that one might not have the right prerequisites or life experiences to deal with in a good way. Another important factor is the peer-pressure that might be harder to resist when one is young and not that self-confident. Brewer, et $\mathrm{al}^{48}$ emphasized that younger and unmarried subjects were more likely to continue substance use compared to older and married subjects. The same tendency was found in a Swedish study by Davstad, Stenbacka, Leifman, Beck, Korkmaz, Romelsjo, ${ }^{55}$ where age was related to the proportion of discharged OMT patients. Patients at age $\leq 30$ had a higher discharge rate than patient aged $\geq 41$ years, and $45 \%$ of involuntarily discharges were based on substance use often in relation to other discharge criteria. A similar association was found in our study: younger age at substance use onset was significantly related with a higher polydrug use while in OMT. However, we did not find an association between age at opioid onset use and opioid use while in OMT. This is in contrast to Soyka, Zingg, Koller, Kuefner ${ }^{56}$ which stated that age at commencement of continuous opioid use was significantly related to treatment dropout: the younger the participant was at the beginning of regular opioid use the more likely they were to drop out of OMT. We did not examine OMT participants' dropout rate; nonetheless, research shows a close link between younger age and dropout. $^{18,57,58}$

\section{Strengths and Limitations}

When interpreting these results, some limitations must be taken into account. The current study was based on a relatively small sample, which reduces the power to detect weaker findings. We were still able to detect individual change and correlates of change. Besides, this study consists of self-selected participants in a limited geographical area. Thus, we cannot claim our results to be representative for the Norwegian OMT population. Nevertheless, there were significant similarities between participants' sociodemographic characteristics and the Norwegian OMT population.

The validity of self-reported drug use has been questioned: Magura, Kang ${ }^{59}$ found that self-reported substance use often was underreported by individuals in a drug use population. Several studies uses urine tests to validate participants' self-reported data. ${ }^{60-63}$ The lack of such tests is a limitation in our study; it could have improved the validity of our results. Even if research shows that substance abusers' self-reports vary depending on the type of the used substance, research also shows that selfreports are consistent with urine tests, and therefore can be a reliable data source. ${ }^{63-65}$ Additionally, self-selected participants may be more committed to the study, and the short-recall periods in our study can lead to a more accurate reporting.

Other studies have detected effects of domain-specific QOL indicators such as social QOL ${ }^{66,67}$ and environmental QOL, ${ }^{67-69}$ while our study did not find such relationships. Several methodological factors might have contributed to our study not detecting any domain-specific associations: the sample size was not big enough to detect any impact, other domains besides those we examined may have affected the overall QOL, or the QOL-questions in KVARUS were to general and did not make explicit casual relations among issues and substance use. ${ }^{42}$ 
OMT participants' natural treatment progression is rarely examined, ${ }^{66}$ but the current study examines participants' adverse experiences, resources, polydrug use, and their potential change in treatment progression. This is one of the uniqueness of this study. In addition, the frequency of the follow-up, every third month, is a strength due to reduced recall bias. Participants are to a greater extent enabled to recall events that happened within a three months' time, in contrast to events that had a longer recall period. $^{70}$

\section{Conclusion}

The main objective was to examine the association between OMT and subsequent polydrug use/opioid use, and whether social factors and QOL were associated with such use during the first 12 months in OMT. Our results show that OMT is significantly related to patients' opioid use, but seems to be less important when it comes to polydrug use. This is also in line with previous research. Our findings add QOL as an important factor in relation to opioid use during OMT. Clinicians should therefore give a particular attention to their participants' overall QOL in OMT, because a simple measure of overall QOL can predict whether they are at risk of using opioids. Clinicians can also gain insight to other aspects that can affect the patients' opioid use. This knowledge can be used actively in treatment to improve patient QOL and thereby may help reducing, and potentially prevent, patients from using opioids. With such knowledge, we have a greater opportunity to intervene and reduce dropout from OMT. Besides, the lack of significant results in relation to social dimensions may imply that, apart from age, participants' life story is of minor importance in reducing polydrug use. Rather, it is the participants' current situation that is important.

\section{Acknowledgments}

The authors are grateful for the participants' contribution and for sharing their histories and experiences, and thanks to Silvia Alpers and Zhanna Gaulen for their constructive contributions during the writing process.

\section{Disclosure}

The authors report no conflicts of interest in this work.

\section{References}

1. Dobler-Mikola A, Hattenschwiler J, Meili D, Beck T, Boni E, Modestin J. Patterns of heroin, cocaine, and alcohol abuse during long-term methadone maintenance treatment. $J$ Subst Abuse Treat. 2005;29(4):259-265. doi:10.1016/j.jsat.2005.08.002
2. Soyka M, Strehle J, Rehm J, Buhringer G, Wittchen HU. Six-year outcome of opioid maintenance treatment in heroin-dependent patients: results from a naturalistic study in a nationally representative sample. Eur Addict Res. 2017;23(2):97-105. doi:10.1159/000468518

3. Mattick RP, Breen C, Kimber J, Davoli M. Methadone maintenance therapy versus no opioid replacement therapy for opioid dependence. Cochrane Database Syst Rev. 2009;3:Cd002209.

4. Gossop M, Stewart D, Browne N, Marsden J. Methadone treatment for opiate dependent patients in general practice and specialist clinic settings: outcomes at 2-year follow-up. J Subst Abuse Treat. 2003;24 (4):313-321. doi:10.1016/S0740-5472(03)00040-0

5. Lind B, Chen S, Weatherburn D, Mattick R. The effectiveness of methadone maintenance treatment in controlling crime an australian aggregate-level analysis. $\mathrm{Br} J$ Criminol. 2005;45(2):201-211. doi:10.1093/bjc/azh085

6. Clausen T, Anchersen K, Waal H. Mortality prior to, during and after opioid maintenance treatment (OMT): a national prospective cross-registry study. Drug Alcohol Depend. 2008;94(1-3):151-157. doi:10.1016/j.drugalcdep.2007.11.003

7. Wagner E, Raabe F, Martin G, et al. Concomitant drug abuse of opioid dependent patients in maintenance treatment detected with a multi-target screening of oral fluid. Am $J$ Addict. 2018;27 (5):407-412. doi:10.1111/ajad.12737

8. Sees KL, Delucchi KL, Masson C, et al. Methadone maintenance vs 180-day psychosocially enriched detoxification for treatment of opioid dependence: a randomized controlled trial. JAMA. 2000;283 (10):1303-1310. doi:10.1001/jama.283.10.1303

9. Nosyk B, Sun H, Evans E, et al. Defining dosing pattern characteristics of successful tapers following methadone maintenance treatment: results from a population-based retrospective cohort study. Addiction. 2012;107(9):1621-1629. doi:10.1111/j.1360-0443.2012. 03870.x

10. EMCDDA. European Drug Report 2018: Trends and Developments. Lisbon: EMCCDA (European Monitoring Centre for Drugs and Drug Addiction); 2018.

11. Tran BX, Ohinmaa A, Mills S, et al. Multilevel predictors of concurrent opioid use during methadone maintenance treatment among drug users with HIV/AIDS. PLOS ONE. 2012;7(12):e51569. doi:10.1371/journal.pone.0051569

12. Specka M, Bonnet U, Heilmann M, Schifano F, Scherbaum N. Longitudinal patterns of benzodiazepine consumption in a German cohort of methadone maintenance treatment patients. Human Psychopharmacol Clin Exp. 2011;26(6):404-411. doi:10.1002/ hup. 1222

13. Srivastava A, Kahan M, Ross S. The effect of methadone maintenance treatment on alcohol consumption: a systematic review. J Subst Abuse Treat. 2008;34(2):215-223. doi:10.1016/j.jsat.2007.04.001

14. Waal H, Bussesund K, Clausen T, Lillevold PH, Skeie I. Statusrapport 2017. LAR 20 år. Status, vurderinger og perspektiver (Status Report. OMT 20 Years. Status, Reviews and Perspectives). Oslo: Senter for rus- og avhengighetsforskning og Nasjonal kompetanstjeneste TSB; 2018.

15. Heikman PK, Muhonen LH, Ojanperä IA. Polydrug abuse among opioid maintenance treatment patients is related to inadequate dose of maintenance treatment medicine. BMC Psychiatry. 2017;17(1):245. doi:10.1186/s12888-017-1415-y

16. Heikman PK, Sundstrom M, Pelander A, Ojanpera IA. New psychoactive substances as part of polydrug abuse within opioid maintenance treatment revealed by comprehensive high-resolution mass spectrometric urine drug screening. Human Psychopharmacol Clin Exp. 2016;31(1):44-52. doi:10.1002/hup.2512

17. Raffa JD, Grebely J, Tossonian H, et al. The impact of ongoing illicit drug use on methadone adherence in illicit drug users receiving treatment for HIV in a directly observed therapy program. Drug Alcohol Depend. 2007;89(2-3):306-309. doi:10.1016/j.drugalcdep. 2007.02.007 
18. White WL, Campbell MD, Spencer RD, Hoffman HA, Crissman B, DuPont RL. Patterns of abstinence or continued drug use among methadone maintenance patients and their relation to treatment retention. J Psychoactive Drugs. 2014;46(2):114-122. doi:10.1080/ 02791072.2014.901587

19. Makarenko I, Mazhnaya A, Marcus R, et al. Concurrent drug injection during opioid agonist treatment among people who inject drugs in Ukraine. J Subst Abuse Treat. 2018;87:1-8. doi:10.1016/j.jsat.2018. 01.007

20. Luo X, Zhao P, Gong X, et al. Concurrent heroin use and correlates among methadone maintenance treatment clients: a 12-month follow-up study in Guangdong Province, China. Int $J$ Environ Res Public Health. 2016;13:3. doi:10.3390/ijerph13030305

21. EMCCDA. Polydrug Use. EMCDDA 2002 Selected Issue. Lisbon: EMCCDA; 2002.

22. Launonen E, Wallace I, Kotovirta E, Alho H, Simojoki K. Factors associated with non-adherence and misuse of opioid maintenance treatment medications and intoxicating drugs among Finnish maintenance treatment patients. Drug Alcohol Depend. 2016;162:227-235. doi:10.1016/j.drugalcdep.2016.03.017

23. Moratti E, Kashanpour H, Lombardelli T, Maisto M. Intravenous misuse of buprenorphine: characteristics and extent among patients undergoing drug maintenance therapy. Clin Drug Investig. 2010;30 (Suppl 1):3-11. doi:10.2165/11536020-000000000-00000

24. Schuman-Olivier Z, Albanese M, Nelson SE, et al. Self-treatment: illicit buprenorphine use by opioid-dependent treatment seekers. J Subst Abuse Treat. 2010;39(1):41-50. doi:10.1016/j.jsat.2010.03.014

25. Heikman PK, Ojanperä IA. Inadequate dose of opioid-agonist medication is related to misuse of benzodiazepines. Addict Disord Their Treat. 2009;8(3):145-153. doi:10.1097/ADT.0b013e31817ea8b8

26. Roux P, Villes V, Blanche J, et al. Buprenorphine in primary care: risk factors for treatment injection and implications for clinical management Drug Alcohol Depend. 2008;97(1):105-113. doi:10.1016/j.drugalcdep. 2008.03.025

27. Muller AE, Bjornestad R, Clausen T. Dissatisfaction with opioid maintenance treatment partly explains reported side effects of medications. Drug Alcohol Depend. 2018;187:22-28. doi:10.1016/j. drugalcdep.2018.02.018

28. Vidal-Trecan G, Varescon I, Nabet N, Boissonnas A. Intravenous use of prescribed sublingual buprenorphine tablets by drug users receiving maintenance therapy in France. Drug Alcohol Depend. 2003;69 (2):175-181. doi:10.1016/S0376-8716(02)00312-5

29. Kopak AM, Proctor SL, Hoffmann NG. The cumulative risk associated with demographic background characteristics among substance use treatment patients. Addict Res Theory. 2017;25(3):216-224. doi:10.1080/16066359.2016.1265109

30. Reimer J, Wright N, Somaini L, et al. The impact of misuse and diversion of opioid substitution treatment medicines: evidence review and expert consensus. Eur Addict Res. 2016;22(2):99-106. doi:10.1159/000438988

31. Roux P, Villes V, Bry D, et al. Buprenorphine sniffing as a response to inadequate care in substituted patients: results from the Subazur survey in south-eastern France. Addict Behav. 2008;33(12):1625-1629. doi:10.1016/j.addbeh.2008.07.018

32. Carlsen S-EL, Lunde L-H, Torsheim T. Predictors of quality of life of patients in opioid maintenance treatment in the first year in treatment Cogent Psychol. 2019;6(1):1-14. doi:10.1080/23311908.2019.156 5624

33. World Health Organization. WHOQOL-BREF: Introduction, Administration, Scoring and Generic Version of the Assessment: Field Trial Version, December 1996. Geneva: World Health Organization; 1996.

34. International Wellbeing Group. Personal Wellbeing Index:. 5th. ISBN No: 978-1-74156-177-7. Melbourne, Australia: The Australian Centre on Quality of Life, Deakin University; 2013.
35. Tomyn AJ, Tyszkiewicz MDF, Cummins RA. The personal wellbeing index: psychometric equivalence for adults and school children. $J$ Social Indic Res. 2013;110(3):913-924. doi:10.1007/s11205-011-9964-9

36. World Health Organization. Field Trial WHOQOL-100 February 1995: The 100 Questions with Response Scales. Geneva: World Health Organization; 1995.

37. Carlsen S-EL, Torsheim T. Self-reported adverse experiences and age of opioid onset for first time admitted to opioid maintenance treatment. Heroin Addict Relat Clin Prob. 2019;21(3):17-26.

38. Maremmani I, Pani PP, Pacini M, Perugi G. Substance use and quality of life over 12 months among buprenorphine maintenance-treated and methadone maintenance-treated heroin-addicted patients. J Subst Abuse Treat. 2007;33:91-98.

39. Ministry of Health and Care Services. Samhandlingsreformen. Rett behandling - på rett sted - til rett tid (The Cooperation reform. Right treatment - at the right place - at the right time). Helse - og omsorgsdepartementet. Vol St. meld. nr. 47. Oslo: Department for public publications; 6/2009 retrieved from regjeringen.no/contentas $\mathrm{sets} / \mathrm{df} 40 \mathrm{e} 16 \mathrm{ad} 32 \mathrm{e} 4 \mathrm{bb} 8 \mathrm{~d} 8 \mathrm{ab} 5 \mathrm{c} 21445 \mathrm{a} 5 \mathrm{dc} / \mathrm{no} / \mathrm{pdfs} / \mathrm{stm} /$ 2008200947000dddpdfs.pdf.

40. Lions C, Carrieri M, Michel L, et al. Predictors of non-prescribed opioid use after one year of methadone treatment: an attributable-risk approach (ANRS-Methaville trial). Drug Alcohol Depend. 2014;135:1-8. doi:10.1016/j.drugalcdep.2013.10.018

41. Bolek S, Yargic I, Ekinci O. The effects of buprenorphine/naloxone maintenance treatment on the quality of life, substance use and functionality in opiate dependence: a follow-up study. Klinik Psikofarmakoloji Bülteni-Bulletin Clin Psychopharmacol. 2016;26 (2):141-151. doi:10.5455/bcp.20151101022909

42. Kiluk BD, Fitzmaurice GM, Strain EC, Weiss RD. What defines a clinically meaningful outcome in the treatment of substance use disorders: reductions in direct consequences of drug use or improvement in overall functioning? Addiction. 2019;114(1):9-15. doi:10. 1111/add.v114.1

43. Van den Brink W, Haasen C. Evidenced-based treatment of opioid-dependent patients. Can j Psychiatry Revue Canadienne De Psychiatr. 2006;51(10):635-646. doi:10.1177/070674370605101003

44. Norwegian Directorate of Health. National Guidelines for Opioid Maintenance Treatment. Oslo: Norwegian Directorate of Health; 2010.

45. Muller AE. Quality of Life, Substance Use Disorders, and Social Lives. Exploring One-Year Outcomes and Intrinsic Links. University of Oslo: Institute of Clinical Medicine, Institute of Clinical Medicine; 2017.

46. Laudet AB, Becker JB, White WL. Don't wanna go through that madness no more: quality of life satisfaction as predictor of sustained remission from illicit drug misuse. Subst Use Misuse. 2009;44:227-252.

47. Mutasa HCF. Risk factors associated with noncompliance with methadone substitution therapy (MST) and relapse among chronic opiate users in an Outer London community. $J$ Adv Nurs 2001;35 (1):97-107. doi:10.1046/j.1365-2648.2001.01826.x

48. Brewer DD, Catalano RF, Haggerty K, Gainey RR, Fleming CB. A meta-analysis of predictors of continued drug use during and after treatment for opiate addiction. Addiction. 1998. doi:10.1046/j.13600443.1998.931738.x

49. Vogel M, Dürsteler-MacFarland KM, Walter M, et al. Prolonged use of benzodiazepines is associated with childhood trauma in opioid-maintained patients. Drug Alcohol Depend. 2011;119 (1):93-98. doi:10.1016/j.drugalcdep.2011.05.037

50. Douglas KR, Chan G, Gelernter J, et al. Adverse childhood events as risk factors for substance dependence: partial mediation by mood and anxiety disorders. Addict Behav. 2010;35(1):7-13. doi:10.1016/j. addbeh.2009.07.004

51. Kjoesnes R, Waal H, Hauff E, Gossop M. Severe trauma among substance users in opioid maintenance treatment: users' assessment of worst trauma and clinical assessment of PTSD. Heroin Addict Relat Clin Probl. 2017;19(1):5-12. 
52. Taplin C, Saddichha S, Li K, Krausz MR. Family history of alcohol and drug abuse, childhood trauma, and age of first drug injection. Subst Use Misuse. 2014;49(10):1311-1316. doi:10.3109/10826084.2014.901383

53. Betts KS, Chan G, McIlwraith F, et al. Differences in polysubstance use patterns and drug-related outcomes between people who inject drugs receiving and not receiving opioid substitution therapies. Addiction. 2016;111(7):1214-1223. doi:10.1111/add.v111.7

54. Behrendt S, Wittchen HU, Hofler M, Lieb R, Beesdo K. Transitions from first substance use to substance use disorders in adolescence: is early onset associated with a rapid escalation? Drug Alcohol Depend. 2009;99(1-3):68-78. doi:10.1016/j.drugalcdep.2008.06.014

55. Davstad I, Stenbacka M, Leifman A, Beck O, Korkmaz S, Romelsjo A. Patterns of illicit drug use and retention in a methadone program: a longitudinal study. J Opioid Manag. 2007;3(1):27-34. doi:10.5055/jom.2007.0036

56. Soyka M, Zingg C, Koller G, Kuefner H. Retention rate and substance use in methadone and buprenorphine maintenance therapy and predictors of outcome: results from a randomized study. Int J Neuropsychopharmacol. 2008;11(5):641-653. doi:10.1017/S146114570700836X

57. Schuman-Olivier Z, Weiss RD, Hoeppner BB, Borodovsky J, Albanese MJ. Emerging adult age status predicts poor buprenorphine treatment retention. J Subst Abuse Treat. 2014;47(3):202-212. doi:10.1016/j.jsat.2014.04.006

58. Marcovitz DE, McHugh RK, Volpe J, Votaw V, Connery HS. Predictors of early dropout in outpatient buprenorphine/naloxone treatment. Am J Addict. 2016;25(6):472-477. doi:10.1111/ajad.v25.6

59. Magura S, Kang S-Y. Validity of self-reported drug use in high risk populations: a meta-analytical review. Subst Use Misuse. 1996;31 (9):1131-1153. doi:10.3109/10826089609063969

60. van den Berg JJ, Adeyemo S, Roberts MB, et al. Comparing the validity of self-report and urinalysis for substance use among former inmates in the Northeastern United States. Subst Use Misuse. 2018;53 (10):1756-1761. doi:10.1080/10826084.2018.1432646

61. Chen T, Zhong N, Du J, et al. Polydrug use patterns and their impact on relapse among heroin-dependent patients in Shanghai, China. Addiction. 2019;114(2):259-267. doi:10.1111/add.14451
62. Arfer KB, Tomlinson M, Mayekiso A, Bantjes J, van Heerden A, Rotheram-Borus M. Criterion validity of self-reports of alcohol, Cannabis, and Methamphetamine use among young men in Cape Town, South Africa. Int J Mental Health Add. 2018;16(1):45-52. doi:10.1007/s11469-017-9769-4

63. Solbergsdottir E, Bjornsson G, Gudmundsson LS, Tyrfingsson T, Kristinsson J. Validity of self-reports and drug use among young people seeking treatment for substance abuse or dependence. $J$ Addict Dis. 2004;23(1):29-38. doi:10.1300/J069v23n01_03

64. Hjorthøj CR, Hjorthøj AR, Nordentoft M. Validity of timeline followback for self-reported use of cannabis and other illicit substances systematic review and meta-analysis. Addict Behav. 2012;37 (3):225-233. doi:10.1016/j.addbeh.2011.11.025

65. Napper LE, Fisher DG, Johnson ME, Wood MM. The reliability and validity of drug users' self reports of amphetamine use among primarily heroin and cocaine users. Addict Behav. 2010;35(4):350-354. doi:10.1016/j.addbeh.2009.12.006

66. Muller AE, Skurtveit S, Clausen T. Building abstinent networks is an important resource in improving quality of life. Drug Alcohol Depend. 2017;180:431-438. doi:10.1016/j.drugalcdep.2017.09.006

67. Chou Y-C, Shih S-F, Tsai W-D, Li C-S, Xu K, Lee TS-H. Improvement of quality of life in methadone treatment patients in northern Taiwan: a follow-up study. BMC Psychiatry. 2013;13 (1):190. doi:10.1186/1471-244X-13-190

68. Padaiga Z, Subata E, Vanagas G. Outpatient methadone maintenance treatment program. Quality of life and health of opioid-dependent persons in Lithuania. Medicina (Kaunas). 2007;43(3):235-241. doi:10.3390/medicina43030029

69. Mitchell SG, Gryczynski J, Schwartz RP, et al. Changes in quality of life following buprenorphine treatment: relationship with treatment retention and illicit opioid use. J Psychoactive Drugs. 2015;47 (2):149-157. doi:10.1080/02791072.2015.1014948

70. Fadnes LT, Taube A, Tylleskar T. How to identify information bias due to self-reporting in epidemiological research. Internet J Epidemiol. 2009;7(2):1-10.
Substance Abuse and Rehabilitation

\section{Publish your work in this journal}

Substance Abuse and Rehabilitation is an international, peerreviewed, open access journal publishing original research, case reports, editorials, reviews and commentaries on all areas of addiction and substance abuse and options for treatment and rehabilitation. The manuscript management system is completely online and includes a very quick and fair peer-review system. Visit http://www.dovepress. $\mathrm{com} /$ testimonials.php to read real quotes from published authors. 